\title{
LA JUSTICIABILIDAD DE LOS DESCA. UNA APROXIMACIÓN AL DERECHO A CONDICIONES EQUITATIVAS $Y$ SATISFACTORIAS QUE GARANTICEN LA SALUD DE LAS PERSONAS TRABAJADORAS
}

\section{THE JUSTICIABILITY OF THE ESCER. AN APPROACH TO THE RIGHT TO JUST AND FAVOURABLE CONDITIONS THAT GUARANTEE THE HEALTH OF WORKERS}

\section{Andrés Oscar De Cicco ${ }^{1}$}

DOI: https://doi.org/10.37767/2591-3476(2021)08

Comentario a

Caso Spoltore vs. Argentina. Excepción Preliminar, Fondo, Reparaciones y Costas.

Sentencia de 9 de junio de 2020

Corte Interamericana de Derechos Humanos

\section{Disponible en}

https://bit.ly/3EAE2vz

RESUMEN:

El caso presentado ante la Corte Interamericana de Derechos Humanos se vincula con la demora y la denegación de justicia sufrida por Victorio Spoltore, en el marco de un proceso laboral derivado de una demanda por indemnización emergente de enfermedad profesional contra una empresa privada. La sentencia reviste de una contundencia e importancia tanto para el Sistema Interamericano de Derechos Humanos como para los sistemas jurídicos locales de la región ya que, por primera vez, se reconoce el derecho a condiciones equitativas y satisfactorias que aseguren la salud en el trabajo como un derecho humano autónomo. En lo escencial, el máximo tribunal de derechos humanos de la región condena a un Estado miembro como responsable directo por la violación

1 Abogado (UNC); Magíster en Gobernanza y Derechos Humanos (Universidad Autónoma de Madrid); Maestrando en Derecho Internacional de los Derechos Humanos (UBA). Mail: deciccoandres@gmail.com. ORCID iD: https://orcid.org/0000-0001-7833-6266. 
del art. 26 de la Convención Americana sobre Derechos Humanos, que consagra los denominados derechos económicos, sociales, culturales y ambientales en conexión con el acceso a la justicia y con la obligación de respetar, proteger y garantizar dichos derechos.

\section{ABSTRACT}

The case presented before the Inter-American Court of Human Rights is related to the delay and denial of justice suffered by Victorio Spoltore, in the framework of a labor action originated from a claim for compensation arising from occupational disease against a private company. The judgment is a significant precedent both for the inter-American system and for the local legal systems of the region since, for the first time, the right to just and favourable conditions that ensure the health of a worker is recognized as an autonomous human right. In essence, the highest court of human rights in the region condemns a member state as directly responsible for the violation of art. 26 of the American Convention on Human Rights, which establishes the economic, social, cultural and environmental rights in connection with access to justice and the obligation to respect, protect and guarantee these rights.

PALABRAS CLAVE: Derechos humanos; DESCA; justiciabilidad; derecho a condiciones equitativas y satisfactorias; derecho a la salud.

KEY WORDS: Human rights; ESCR; justiciability; right to just and favourbale conditions to work; right to health

\section{I.Introducción}

El caso se centra en la figura de la presunta víctima Victorio Spoltore, argentino, fallecido en 2012, quien desde 1963 desempeñó tareas bajo relación de dependencia para la empresa privada Cacique Camping S.A. en la Provincia de Buenos Aires, Argentina. En 1985, ante los tribunales nacionales del país, Spoltore interpone una demanda laboral contra le empresa empleadora solicitando el pago de una indemnización por enfermedad e incapacidad laboral y daño moral. Agotadas las vías recursivas internas, luego del transcurso de más de 12 años de litigio judicial en el fuero doméstico, en el 2001 el peticionante recurre a instancias internacionales e inicia el proceso judicial ante el Sistema Interamericano de Derechos Humanos alegando responsabilidad de la República de Argentina por la denegación de justicia y la demora excesiva en el proceso judicial laboral interno, amparándose en la Convención Americana sobre Derechos Humanos. Fueron necesarios 18 años más para que, finalmente, el 9 de junio de 2020 la Corte Interamericana de Derechos Humanos conozca sobre el fondo del asunto y declare al Estado argentino responsable internacional de violar la Convención.

A partir del caso Lagos del Campo vs. Perú (2017), la Corte Interamericana de Derechos Humanos plantea un antes y un después en cuanto al criterio de justiciabilidad de los derechos económicos, sociales, culturales y ambientales en el sistema interamericano al considerar que los derechos laborales son derechos humanos autónomos y de exigibilidad inmediata reconocidos en el art. 26 de la Convención Americana sobre Derechos 
Humanos. Siguiendo con esa misma línea jurisprudencial y argumentativa, en el caso puesto bajo análisis, el tribunal confirma esta postura y da un nuevo paso, al afirmar que el derecho a condiciones de trabajo equitativas y satisfactorias que aseguren la salud de personas trabajadoras forma parte del derecho al trabajo y, en efecto, queda alcanzado por las disposiciones del art. 26.

Con la finalidad de comprender la trascendencia de la decisión puesta bajo análisis, será necesario conocer previamente el alcance de la exigibilidad de los derechos económicos, sociales, culturales y ambientales a través de su tratamiento tanto en el contexto universal como interamericano.

\section{La justiciabilidad de los derechos humanos \\ 1. En el Sistema Universal}

Los derechos humanos son universales, indivisibles, irrenunciables, interdependientes y de desarrollo progresivo. Estas características son plenamente aplicables a todos los derechos fundamentales sin distinción sean civiles, políticos, económicos, sociales, culturales o ambientales. No obstante, la historia del derecho internacional público y del derecho internacional de los derechos humanos nos ha revelado que lograr la unicidad de los derechos humanos en un solo cuerpo normativo lejos estaría de ser una tarea facil.

Con la aprobación de la Declaración Universal de Derechos Humanos en $1948^{2}$ se crea una base o punto de partida de derechos fundamentales para toda la humanidad, reconociendo en un mismo manifiesto no sólo derechos civiles y políticos sino derechos económicos, sociales y culturales. Esta equiparación de derechos reviste gran importancia ya que implica la superación de la categorización de los derechos en distintas generaciones o especies pues son, en primer lugar y sin atisbo de duda, derechos humanos $y$, en segundo lugar, indisociables entre sí para su plena satisfacción (Salamero Teixidó, 2012: 19).

Posteriormente a la Declaración, surge la necesidad de crear un instrumento jurídicamente vinculante que contenga los derechos allí consagrados como así también la configuración de un sistema de protección y monitoreo de dichos derechos y garantías. Cabe resaltar que la tarea encomendada por la Asamblea General de Naciones Unidas a la Comisión de Derechos Humanos (hoy extinta) resultó sumamente compleja dadas las constantes demoras, estancamientos y presiones recibidas en un contexto mundial signado por la bipolaridad y la dualidad política e ideológica entre los bloques de Occidente y Oriente. Por un lado, los Estados del Este evasivos al reconocimiento de derechos civiles y políticos y, por el otro, Estados occidentales (en su mayoría liberales) con ciertas objeciones en la aplicabilidad de los derechos económicos, sociales y culturales (en adelante "DESC"). Si bien en las sesiones llevadas adelante por la Comisión había un consenso general en cuanto los DESC revestían igual importancia que los derechos civiles y políticos, se entendía que estos no eran justiciables y que su método de implementación era diferente. Finalmente, con el objetivo de reconciliar opiniones opuestas y de lograr el mayor grado de compromiso entre los diferentes Estados, en 1966 la Asamblea General de Naciones Unidas termina adoptando dos instrumentos jurídicos distintos diferenciando los derechos fundamentales en dos bloques: el Pacto Internacional de Derechos Civiles

2 ONU: Asamblea General, Declaración Universal de los Derechos Humanos. Adoptado por Resolución de la Asamblea General 217 A (III), el 10 de diciembre de 1948 en París. Disponible en: https://www.un.org/es/about-us/universal-declaration-of-human-rights. 
y Políticos 3 , por un lado, y el Pacto Internacional de Derechos Económicos, Sociales y Culturales ${ }^{4}$, por el otro (Salvioli, 2016: 79).

La presunta falta de justiciabilidad de los DESC es una cuestión sumamente discutida hasta nuestros días y que ha tenido sus efectos tanto en el orden internacional como en el doméstico. Pese a la existencia de un corpus iuris universal ${ }^{5}$ que consagra la interdependencia e indivisibiidad de los derechos humanos y pone en un mismo nivel de jerarquía a los derechos civiles y políticos y los DESC, desde la propia doctrina y la práctica internacional han existido diversas formas de abordar cada grupo de derechos, donde los primeros han tenido una mayor preminencia o han sido considerados como verdaderos derechos fundamentales a proteger, mientras que los segundos suelen ser reconocidos como un conjunto de buenas intenciones carentes de exigibilidad o de exigibilidad derivada.

Este tipo de discriminación en favor de los derechos civiles y políticos, por lo pronto en el sistema interamericano de protección de derechos humanos, ha quedado saldada como veremos en el próximo apartado.

\section{En el Sistema Interamericano}

En el marco americano, tanto la Declaración Americana de los Derechos y Deberes del Hombre ${ }^{6}$ como la Convención Americana sobre Derechos Humanos ${ }^{7}$ hacen mención expresa a los derechos económicos, sociales, culturales y ambientales (en adelante "DES$C^{\prime \prime}$ ). Desde abril de 1948 la Declaración menciona entre su listado de derechos aquellos relacionados a los DESCA tales como el derecho a la constitución y protección de la familia (art. VI); derecho de protección a la maternidad y a la infancia (art. VII); derecho a la preservación de la salud y al bienestar (art. XI); derecho a la educación (art. XII); derecho a los beneficios de la cultura (art. XIII); derecho al trabajo y a una justa retribución (art. $\mathrm{XIV)}$; derecho al descanso y a su aprovechamiento (art. XV); derecho a la seguridad social $(\mathrm{XVI})$; derecho de reunión (art. XXI); derecho de asociación (art. XXII).

Por su parte, la Convención Americana sobre Derechos Humanos (en adelante, "la Convención" o "CADH"), instrumento vinculante para los Estados ratificantes, hace un reconocimiento expreso en su Preámbulo en favor de la indivisibilidad e interdependencia de los derechos humanos al declarar que "con arreglo a la Declaración Universal de los Derechos Humanos, sólo puede realizarse el ideal del ser humano libre, exento del temor y de la miseria, si se crean condiciones que permitan a cada persona gozar de sus derechos económicos, sociales y culturales, tanto como de sus derechos civiles y políticos".

3 ONU: Asamblea General, Pacto Internacional de Derechos Civiles y Políticos. Adoptado y abierto a la firma, ratificación y adhesión por la Asamblea General en su resolución 2200 A (XXI), de 16 de diciembre de 1966, 16 diciembre 1966. Disponible en: https://www.ohchr.org/sp/professionalinterest/pages/ccpraspx.

4 ONU: Asamblea General, Pacto Internacional de Derechos Económicos, Sociales y Culturales. Adoptado y abierto a la firma, ratificación y adhesión por la Asamblea General en su resolución 2200 A (XXI), de 16 de diciembre de 1966, 16 diciembre 1966. Disponible en: https://www.ohchr.org/sp/professionalinterest/ pages/cescr.aspx.

5 Declaración Universal de Derechos Humanos (1948) art. 22 y ss.; Conferencia de Viena con la Declaración y Programa de Acción (1993) “5. All human rights are universal, indivisible and interdependent and interrelated. The international community must treat human rights globally in a fair and equal manner, on the same footing, and with the same emphasis. While the significance of national and regional particularities and various historical, cultural and religious backgrounds must be borne in mind, it is the duty of States, regardless of their political, economic and cultural systems, to promote and protect all human rights and fundamental freedoms."; Carta Africana sobre los Derechos Humanos y de los Pueblos (1981), Preámbullo; Protocolo Facultativo del Pacto Internacional de Derechos Económicos, Sociales y Culturales (2008); Directrices de Maastricht sobre violaciones a derechos Económicos, Sociales y Culturales (1997).

6 Organización de los Estados Americanos (OEA), Declaración Americana de los Derechos y Deberes del Hombre, 30 abril 1948, disponible en: http://www. oas.org/es/cidh/mandato/Basicos/declaracion.asp.

7 Organización de los Estados Americanos (OEA), Convención Americana sobre Derechos Humanos "Pacto de San José de Costa Rica", 22 noviembre 1969, disponible en: https://www.oas.org/dil/esp/1969_Convenci\%C3\%B3n_Americana_sobre_Derechos_Humanos.pdf 
Sin embargo, pese a esta consagración, el contexto de la guerra fría no resultó ajeno a su configuración y como resultado la segmentación de derechos se plasmó en su articulado. De este modo, el Capítulo II concerniente a derechos civiles y políticos identifica e individualiza en particular un conjunto de derechos, mientras que el Capítulo III relativo a los DESCA no tiene una individualización de derechos en concreto, sino que contempla un único artículo: “Art. 26: Los Estados Partes se comprometen a adoptar providencias, tanto a nivel interno como mediante la cooperación internacional, especialmente económica y técnica, para lograr progresivamente la plena efectividad de los derechos que se derivan de las normas económicas, sociales y sobre educación, ciencia y cultura, contenidas en la Carta de la Organización de los Estados Americanos, reformada por el Protocolo de Buenos Aires, en la medida de los recursos disponibles, por vía legislativa u otros medios apropiados.

Como se puede apreciar, de la Convención no se desprenden cuáles son los derechos protegidos en concreto en materia DESCA, sino que el artículo que los reconoce remite a aquellos que derivan de las disposiciones de la Carta de la OEA. Además, sin mayores precisiones, obliga a los Estados para que de forma progresiva y conforme a los recursos disponibles tomen las medidas que sean necesarias tanto en el orden interno como mediante la cooperación con otros Estados a los fines de lograr la plena efectividad y no regresividad de los DESCA.

Con la finalidad de atenuar esta amplitud y ambigüedad planteada por el art. 26, en 1988 se adoptó el protocolo adicional a la CADH en materia de DESCA (también llamado "Protocolo de San Salvador") $)^{8}$ fortaleciendo la vigencia y exigibilidad de estos derechos en la región, en el que se consagran una serie de derechos fundamentales como por ejemplo el derecho al trabajo; a las condiciones justas, equitativas y satisfactorias de trabajo; derechos sindicales; derecho a la salud y a la seguridad social; derecho a la educación; derecho a la alimentación; entre otras.

A partir de esta configuración, dentro del Sistema Interamericano de Derechos Humanos se debatió, por un lado, cómo debía ser interpretada esta idea de progresividad y disponibilidad de recursos a la hora de responsabilizar a un Estado parte por violación a los DESCA y, por el otro, el alcance de su justiciabilidad, es decir si debían ser protegidos, y a su vez juzgados, de forma autónoma e independiente o de forma indirecta o derivada de los derechos civiles y políticos.

Sin embargo, cabe señalar que las particularidades mencionadas en el art. 26 no quitan que los DESCA no sean inmediatamente exigibles o que los Estados frente a una posible falta de recursos disponibles no tengan la obligación de garantizarlos. Si los recursos fueran insuficientes, es obligación del Estado de llevar adelante programas o estrategias que aseguren su promoción o, en todo caso, eviten su regresividad. Como ha explicado MÓNICA PINTO, la progresividad apuntada no exime a los Estados partes de la obligación mínima de asegurar la satisfacción de por lo menos niveles esenciales de cada uno de los derechos protegidos; la dignidad del ser humano no puede ser compartimentada bajo ninguna circunstancia (Pinto, 2009: 57).

\section{Criterio seguido por la Corte Interamericana de Derechos Humanos}

8 Organización de los Estados Americanos (OEA), Protocolo Adicional a la Convención Americana de Derechos Humanos en materia de Derechos Económicos, Sociales y Culturales, "Protocolo de San Salvador", 17 de noviembre de 1988, disponible en: http://www.oas.org/juridico/spanish/tratados/a-52.html. 
Dentro del campo de acción de la Corte Interamericana de Derechos Humanos (en adelante "la Corte", "Corte IDH" o "Tribunal de San José"), hasta no hace mucho tiempo se declaraba no competente para entender en casos de violaciones al art. 26, tal como ocurrió en el fallo "Cinco Pensionistas" vs. Perú (2003) ${ }^{9}$, en donde se interpretaba la violación de dicho artículo de una forma derivada a la violación de un derecho civil o político reconocido en la Convención ${ }^{10}$. Con el paso de los años, el criterio de la Corte fue evolucionando hasta llegar a la sentencia Acevedo Buendía vs. Perú (2009), donde en su fundamentación se declara competente para considerar violaciones del art. 26 ya que los términos amplios en que está redactada la Convención indican que ejerce una jurisdicción plena sobre todos los artículos y sus disposiciones. Además, la Corte sostiene que la noción de desarrollo progresivo no es óbice para que un Estado no pueda rendir cuentas. No obstante, la Corte no encontró motivos suficientes para declarar incumplido el art. $26 .{ }^{11}$

Como expresa JORGE CALDERÓN GAMBOA "muchos debates se han generado respecto de la justiciabilidad de los DESCA en el ámbito interamericano, postulando puntos discordantes respecto de lo que suponemos que quiso decir la CADH, o bien, los efectos del Protocolo de San Salvador. También es claro que la Corte ya venía brindando "protección indirecta" de algunos DESCA vía los derechos civiles y políticos y, en un caso, mediante el uso del Protocolo de San Salvador. Por otra parte, se presenta otro debate respecto de "la progresividad" (y no regresividad) de estos derechos, lo cual no significa que ello excluye su justiciabilidad, ni implica que no existan "obligaciones de carácter inmediato" en la vigencia de estos derechos, a las cuales les aplican las obligaciones generales de respeto y garantía del tratado" (Calderón Gamboa, 2018: 338).

Finalmente, en este camino de interpretación sobre la exigibilidad de los DESCA y del art. 26 de la Convención, la Corte IDH se expide en la sentencia Lagos del Campo vs Perú $(2017)^{12}$. Aquí el Tribunal de San José condena al Perú como responsable internacional por la violación de los derechos a la libertad de pensamiento y expresión y garantías judiciales reconocidos en la CADH y, más importante aún, condena al Estado de ser responsable por la violación -entre otros- del derecho a la estabilidad laboral, reconocido en el art. 26, y a la libertad de asociación, reconocido en los art. 16 y 26 del mismo instrumento. Es decir, con este decisorio, por primera vez la Corte condena a un Estado por la violación directa y autónoma de un derecho humano perteneciente a los DESCA sin fundarlo en la violación de un derecho civil o político análogo. En efecto, la Corte IDH, a través de esta sentencia, proclama la interdependencia e indivisibilidad de los derechos humanos sean civiles, políticos, económicos, sociales o culturales y garantiza su integralidad y, en particular, ejerce la protección judicial del derecho al trabajo de forma directa y autónoma, a la que los cuerpos normativos domésticos de cada Estado Parte deberán ajustarse.

La línea argumentativa y de interpretación que sigue el máximo tribunal interamericano en Lagos del Campo será luego repetida en el caso Spoltore vs. Argentina (2020), objeto del presente comentario y que procederé a analizar a continuación.

\footnotetext{
9 Corte IDH. Caso “Cinco Pensionistas” vs. Perú. Fondo, Reparaciones y Costas. Sentencia de 28 de febrero de 2003. Serie C, núm. 98.

10 En el caso Cinco Pensionistas vs. Perú, la Corte fundamenta la violación del derecho a la seguridad social en el derecho a la propiedad.

11 Corte IDH. Caso Acevedo Buendía y otros (“Cesantes y Jubilados de la Contraloría”) vs. Perú. Excepción Preliminar, Fondo, Reparaciones y Costas. Sentencia de 1 de julio de 2009. Serie C, núm. 198. Párr. 16, 102, 106.

12 Corte IDH. Caso Lagos del Campo vs. Perú. Excepciones Preliminares, Fondo, Reparaciones y Costas. Sentencia de 31 de agosto de 2017. Serie C, núm. 340.
} 


\section{Spoltore vs. Argentina: análisis del caso. ${ }^{13}$ 1. Hechos. Fuero doméstico.}

En mayo de 1984 el señor Spoltore sufre un infarto durante la jornada laboral en las instalaciones de la empresa Cacique Camping S.A. Como consecuencia de ello, en octubre de 1985 inicia los trámites jubilatorios por incapacidad ante la Caja de Previsión para la Industria, Comercio y Actividades Civiles. Luego de sufrir un segundo infarto en mayo de 1986, la Junta Médica finalmente determina una discapacidad del 70\%. En mayo 1987, a los 50 años de edad, deja de trabajar y comienza a percibir una pensión.

El 30 de junio de 1988 Spoltore interpone demanda laboral contra le empresa solicitando indemnización por enfermedad e incapacidad laboral y daño moral. Alega que, con motivo de su trabajo diario y las presiones sufridas dentro del ámbito laboral, su salud se vio agravada debiendo solicitar el retiro anticipado por incapacidad sobreviniente. En junio de 1997, 9 años después de iniciada la acción legal, el Tribunal del Trabajo Nro. 3 del Departamento Judicial de San Isidro de la Provincia de Buenos Aires dictó sentencia rechazando las pretensiones del demandante argumentando ausencia de responsabilidad de la empresa ante la falta de pruebas.

Frente a la sentencia del tribunal de primera instancia, en septiembre de 1997 Spoltore interpuso ante la Suprema Corte de Justicia de Buenos Aires (en adelante "SCJBA") recurso extraordinario de inaplicabilidad de ley y de nulidad contra la sentencia dictada por el a-quo. Finalmente, el 16 de agosto de 2000 ambos recursos son rechazados por el tribunal de alzada, finalizando así con un proceso judicial que llevó más de 12 años en su totalidad.

Paralelamente a la consecución del proceso de segunda instancia ante la SCJBA, Spoltore presentó en sede administrativa una denuncia disciplinaria ante la Inspección General de la SCJBA argumentando demora del plazo razonable y negligencia en el proceso judicial llevado adelante por el Tribunal del Trabajo. La SCJBA constató la demora en el proceso, pero resolvió que sólo cabía un llamado de atención o apercibimiento a la secretaria del tribunal por la demora en varias diligencias de trámite de la causa.

\section{Fuero Internacional.}

El proceso ante el Sistema Interamericano de Derechos Humanos se da inicio el 11 de septiembre de 2000 a partir de la denuncia presentada por el propio señor Spoltore a través del sistema de peticiones individuales ante la Comisión Interamericana de Derechos Humanos (en adelante "la CIDH", "la Comisión"). El peticionario alega la responsabilidad de la República de Argentina por la violación de derechos consagrados en la Convención Americana sobre Derechos Humanos como consecuencia de la denegación de justicia y demora excesiva en el proceso judicial laboral seguido en contra de la empresa Cacique Camping S.A. ${ }^{14}$.

Luego de declarar admisible el caso, la Comisión, en su Informe de Fondo Nro. 74/17, encuentra al Estado argentino responsable por la violación de los derechos a las garantías judiciales y protección judicial en perjuicio del peticionante. Frente a ello, elabora una serie de recomendaciones al Estado y le concede un plazo de 2 meses para su cumpli-

13 Corte IDH. Caso Spoltore Vs. Argentina. Excepción Preliminar, Fondo, Reparaciones y Costas. Sentencia de 9 de junio de 2020. Serie C No. 404.

14 Informe No. 74/17. Caso 12.656. Informe de Fondo. Victorio Spoltore Argentina. OEA/Ser.L/V/II.163 Doc. 88. 5 de julio 2017. Disponible en: https:// www.oas.org/es/cidh/decisiones/corte/2019/12656FondoEs.pdf. 
miento. Luego de siete pedidos de prórroga y ante la falta de cumplimiento efectivo de las recomendaciones por parte del Estado, en enero de 2019 la Comisión eleva el caso ante la Corte IDH. Resulta importante remarcar que desde el momento de la petición individual hasta el elevamiento de la causa pasaron más de 18 años.

Sometido el caso a jurisdicción de la Corte, los representantes legales de la presunta víctima alegaron, en coincidencia con el Informe de la Comisión, violación de garantías judiciales en virtud del art 8.1 de la Convención ${ }^{15}$ y de protección judicial consagrada en el art. $25.1^{16}$, añadiendo que el Estado también era responsable por violación de los derechos de integridad personal, a gozar de condiciones dignas y satisfactorias de trabajo y al disfrute del más alto nivel posible de salud física y mental, en virtud del art. 26, así como el derecho a recurrir del fallo en virtud del art. 8.2 $\mathrm{h}^{17}$, el deber de adoptar disposiciones de derecho interno y el derecho de protección familiar e integridad personal de los familiares del señor Spoltore.

El Estado demandado, por su parte, alegó como excepción preliminar la falta de agotamiento de los recursos internos, ya que entiende que los recursos interpuestos no eran los pertinentes para resolver el conflicto, sino que el demandante debió agotar la acción de daños y perjuicios contra la Provincia de Buenos Aires en virtud de lo establecido por el Código Civil argentino vigente al momento de los hechos. Asimismo, en forma subsidiaria, el Estado reconoció parcialmente su responsabilidad internacional sólo por la violación del plazo razonable y del derecho a la protección judicial atento a que "(...) el proceso judicial en cuestión no revestía especial complejidad y que, en líneas generales, el interesado que, además no era otro que una persona con discapacidad, dio el impulso esperable al tramite". Y agregó "resulta irrazonable que las autoridades judiciales hayan tardado doce años en dilucidar si le asistía derecho en la demanda por enfermedad profesional contra su empleador".

Como se puede observar, el caso en cuestión se centra exclusivamente en la duración del proceso judicial laboral al que se vio sometido el peticionante y presunta víctima y no en la sentencia denegatoria de indemnización por los tribunales argentinos. Frente al allanamiento parcial que realiza el Estado argentino la misión de la Corte de San José se reconfiguró, en tanto no analiza si hubo violación del plazo razonable y de la protección judicial, sino que se centra exclusivamente en los hechos que tuvieron lugar durante el proceso laboral iniciado por el señor Spoltore y en aquellos denunciados por los representantes que estuvieran íntimamente vinculados al marco fáctico en discusión.

Por lo anteriormente dicho, haciendo un análisis previo sobre la procedencia y el alcance de las violaciones invocadas por los representantes en forma autónoma, la Corte entendió que las únicas controversias jurídicas subsistentes que restaba examinar se encontraban en (i) el derecho a condiciones de trabajo equitativas y satisfactorias que aseguren la salud del trabajador en relación con el acceso a la justicia, y (ii) el derecho a recurrir

\footnotetext{
15 Organización de los Estados Americanos (OEA), Convención Americana sobre Derechos Humanos "Pacto de San José de Costa Rica", 22 noviembre 1969. Art. 8.1 "Toda persona tiene derecho a ser oída, con las debidas garantías y dentro de un plazo razonable por un juez o tribunal competente, independiente e imparcial, establecido con anterioridad por la ley, en la sustanciación de cualquier acusación penal formulada contra ella o para la determinación de sus derechos y obligaciones de orden civil, laboral, fiscal o de cualquier otro carácter"

16 Organización de los Estados Americanos (OEA), Convención Americana sobre Derechos Humanos (...). Art. 25.1: “Toda persona tiene derecho a un recurso sencillo y rápido o a cualquier otro recurso efectivo ante los jueces o tribunales competentes, que la ampare contra actos que violen sus derechos fundamentales reconocidos por la Constitución, la ley o la presente convención, aun cuando tal violación sea cometida por personas que actúen en ejercicio de sus funciones oficiales".

17 Organización de los Estados Americanos (OEA), Convención Americana sobre Derechos Humanos (...). Art. 8.2h): “( ...) Durante el proceso, toda persona tiene derecho, en plena igualdad, a las siguientes garantías mínimas: (...) h) Derecho de recurrir del fallo ante juez o tribunal superior”.
} 
un fallo ante juez o tribunal superior en un proceso laboral por enfermedad profesional.

\section{Decisión.}

La sentencia de la Corte Interamericana de Derechos Humanos fue por tres votos a favor, incluido el voto de la Presidenta de la Corte, y tres votos en contra. Al ser un empate, fue el voto de la Presidenta del tribunal el que decidió.

Como primera medida, el Tribunal de San José decidió rechazar la excepción preliminar esgrimida por Argentina referente a la falta de agotamiento de los recursos internos y aceptar el reconocimiento parcial de responsabilidad hecha por el Estado. Entendió que este reconocimiento de responsabilidad implica aceptación plena de competencia del Tribunal y ello es incompatible con una presunta falta de agotamiento de recursos en sede interna.

En segundo término, la Corte consideró que tanto los recursos extraordinarios interpuestos a la sentencia del tribunal laboral argentino como la denuncia disciplinaria en sede administrativa no eran lo suficientemente efectivos de dar una solución al daño causado por la demora procesal objeto del debate. Asimismo, el Estado argentino no pudo probar fehacientemente que la acción de daños y perjuicios invocada por Spoltore haya sido una vía procesal idónea y efectiva en casos de demoras judiciales excesivas en procesos laborales análogos, ni que brinden a la víctima una reparación total por el daño causado.

Seguidamente la Corte IDH decide sobre el fondo de la cuestión condenando a la República Argentina como responsable internacional de haber vulnerado los derechos reconocidos en la Convención a las garantías judiciales (art. 8.1), protección judicial (art. 25.1), en conexión con el art. 1.1, por la violación del plazo razonable en el proceso judicial laboral en perjuicio de Victorio Spoltore. Asimismo, consideró al Estado responsable internacional de haber vulnerado el derecho a condiciones de trabajo equitativas y satisfactorias que aseguren la salud del trabajador consagrada en el art. 26 de la Convención, en relación con el acceso a la justicia (art. 8.1 y 25.1), en conexión con la obligación de respetar y garantizar dichos derechos (art. 1.1).

Sin embargo, la Corte encontró que la Argentina no era responsable de violar el derecho a recurrir el fallo (art. 8.2.h) atento a que el proceso judicial iniciado por el señor Spoltore no se trataba de un proceso judicial penal que implicara privación de libertad o que fuera un proceso administrativo de naturaleza sancionatoria, sino que solo tenía por finalidad el otorgamiento de una indemnización por presunta enfermedad profesional.

Finalmente, en calidad de medidas reparatorias y siguiendo normas consuetudinarias del Derecho Internacional, instrumentos convencionales regionales de derechos humanos y la jurisprudencia de la Corte, toda violación de una obligación internacional que produzca un daño requiere el deber de repararlo. Por lo tanto, se ordenó que la Argentina publicara el resumen oficial de la sentencia en un diario de amplia circulación nacional, pagar una suma dineraria en concepto de daño inmaterial, gastos y costas en favor de los derechohabientes del señor Spoltore y el reintegro de los gastos ocasionados al Fondo de Asistencia Legal de Víctimas. 


\section{El derecho a condiciones de trabajo equitativas y satisfactorias que aseguren la salud del trabajador}

El derecho al trabajo digno es un derecho humano que todas las personas deben gozar y su garantía es fundamental para la realización de otros derechos fundamentales en pos de una vida digna, plena y saludable. En este sentido, existe una íntima conexión entre el derecho al trabajo y el derecho a condiciones equitativas y satisfactorias de trabajo. La percepción de un salario justo y equitativo, el cumplimiento de condiciones aceptables como seguridad, salud o higiene que aseguren el trabajo, la igualdad de oportunidades laborales o el descanso pago, constituyen algunos de los derechos que garantizan que el trabajo sea ejercido equitativa y satisfactoriamente. Varios instrumentos del Sistema Universal de protección de derechos humanos así lo han reconocido ${ }^{18}$.

Por ejemplo, el Comité de Derechos Económicos, Sociales y Culturales emitió la Observación General Nro.23 sobre el derecho a condiciones de trabajo equitativas y satisfactorias, en donde interpreta el art. 7 del Pacto de DESC y reconoce expresamente que "el disfrute del derecho a condiciones de trabajo equitativas y satisfactorias es un requisito previo y el resultado del disfrute de otros derechos recogidos en el Pacto, por ejemplo el derecho al disfrute del más alto nivel posible de salud física y mental, mediante la prevención de los accidentes laborales y las enfermedades profesionales, y el derecho a un nivel de vida adecuado, mediante una remuneración aceptable". ${ }^{19}$

En el sistema interamericano, a partir del fallo Spoltore vs. Argentina, la Corte IDH avanza un poco más, ya que procede por primera vez a identificar el derecho a condiciones equitativas y satisfactorias que aseguren la salud de trabajadores y trabajadoras, a definir el contenido de estas condiciones y a considerar de qué manera este derecho se ha visto vulnerado en el caso concreto. Siguiendo este razonamiento, la Corte continúa el camino que empezó a trazar a partir de la sentencia Lagos del Campo vs. Perú con los derechos laborales identificando, en este caso, el derecho a condiciones de trabajo equitativas y satisfactorias que aseguren la salud del trabajador o trabajadora como un derecho autónomo que, al relacionarse con los alcances del derecho al trabajo, debe ser protegido por el art. 26 de la Convención.

Asimismo, el tribunal regional también se refirió a las disposiciones de la Carta de la Organización de los Estados Americanos ${ }^{20}$, reformada por el Protocolo de Buenos Aires,

18 Declaración Universal de Derechos Humanos (1948), art. 23.1 "Toda persona tiene derecho al trabajo, a la libre elección de su trabajo, a condiciones equitativas y satisfactorias de trabajo y a la protección contra el desempleo"; Pacto de Derechos Económicos, Sociales y Culturales (1966), art. 7: "Los Estados Partes en el presente Pacto reconocen el derecho de toda persona al goce de condiciones de trabajo equitativas y satisfactorias que le aseguren en especial: a) Una remuneración que proporcione como mínimo a todos los trabajadores: i) Un salario equitativo e igual por trabajo de igual valor, sin distinciones de ninguna especie; en particular, debe asegurarse a las mujeres condiciones de trabajo no inferiores a las de los hombres, con salario igual por trabajo igual; ii) Condiciones de existencia dignas para ellos y para sus familias conforme a las disposiciones del presente Pacto; b) La seguridad y la higiene en el trabajo; c) Igual oportunidad para todos de ser promovidos, dentro de su trabajo, a la categoría superior que les corresponda, sin más consideraciones que los factores de tiempo de servicio y capacidad; d) El descanso, el disfrute del tiempo libre, la limitación razonable de las horas de trabajo y las vacaciones periódicas pagadas, así como la remuneración de los días festivos"; Comité de Derechos Económicos, Sociales y Culturales, Observación General Nro.18 (2005), Párr. 2 "El Pacto Internacional de Derechos Económicos, Sociales y Culturales proclama el derecho al trabajo en un sentido general en su artículo 6 y desarrolla explícitamente la dimensión individual del derecho al trabajo mediante el reconocimiento, en el artículo 7, del derecho de toda persona a condiciones de trabajo equitativas y satisfactorias, en especial la seguridad de las condiciones de trabajo" y Párr. 7 "El trabajo, según reza el artículo 6 del Pacto, debe ser un trabajo digno. Éste es el trabajo que respeta los derechos fundamentales de la persona humana, así como los derechos de los trabajadores en lo relativo a condiciones de seguridad laboral y remuneración. También ofrece una renta que permite a los trabajadores vivir y asegurar la vida de sus familias, tal como se subraya en el artículo 7 del Pacto. Estos derechos fundamentales también incluyen el respecto a la integridad física y mental del trabajador en el ejercicio de su empleo".

19 ONU. Comité de Derechos Económicos, Sociales y Culturales, Observación General No 23 (2016) sobre el derecho a condiciones de trabajo equitativas y satisfactorias (artículo 7 del Pacto Internacional de Derechos Económicos, Sociales y Culturales), 27 de abril de 2016 E/C.12/GC/23. Párr 1. Disponible en: https:// www.escr-net.org/es/recursos/observacion-general-num-23-2016-sobre-derecho-condiciones-trabajo-equitativas-y.

20 Carta de la Organización de Estados Americanos (OEA) (1948), reformada por el Protocolo de Buenos Aires, 27 de febrero de 1967. Disponible en: http://www.oas.org/es/sla/ddi/tratados_multilaterales_interamericanos_A-41_carta_OEA.asp. 
que remite el propio art. 26 de la Convención. En dicho instrumento existen un conjunto de normas que permiten identificar al derecho a condiciones equitativas y satisfactorias que aseguren la salud de los trabajadores y trabajadoras. El artículo 45.b establece: "EI trabajo es un derecho y un deber social, otorga dignidad a quien lo realiza y debe prestarse en condiciones que, incluyendo un régimen de salarios justos, aseguren la vida, la salud y un nivel económico decoroso para el trabajador y su familia, tanto en sus años de trabajo como en su vejez, o cuando cualquier circunstancia lo prive de la posibilidad de trabajar". Seguidamente el artículo 46 llama a los Estados signatarios a facilitar procesos de integración regional y a la armonización de sus legislaciones especialmente en el campo laboral y de la seguridad social para que los derechos de las personas trabajadoras sean igualmente protegidos.

Por otro lado, haciendo uso del criterio amplio de interpretación otorgado por la Convención (art.29), la Corte también se vale de otros instrumentos del corpus iuris internacional que le permiten actualizar y ampliar el sentido de los derechos derivados de la Carta de la OEA que se encuentran expresamente reconocidos en el art. 26. Para ello acude a la Declaración Universal de Derechos Humanos ${ }^{21}$, a las observaciones generales del Comité de Derechos Económicos, Sociales y Culturales (mencionado ut-supra) y al Convenio de la Organización Internacional del Trabajo (OIT) sobre seguridad y salud de los trabajadores $^{22}$. Su nivel de amplitud es tal, que incluso acude a la normativa nacional argentina a través de un análisis del art. 14 bis de la Constitución Nacional y el art. 39.1 de la Constitución de la Provincia de Buenos Aires.

Como resultado de todo este trabajo de interpretación holística y amalgamiento normativo entre diferentes instrumentos, se arriba a una serie de conclusiones que definen el contenido y el alcance del derecho a la salud de las personas trabajadoras en los ámbitos del trabajo. Por un lado, el Tribunal de San José afirma que la prevención de accidentes o enfermedades profesionales por parte de los Estados es una forma de garantizar la salud del trabajador o trabajadora, y Argentina, en el caso en puesto bajo análisis, no cumplió. Por otro lado, consideró que el acceso a una justicia rápida, eficaz e idónea forma parte del derecho laboral y su violación atenta las condiciones de trabajo que aseguran la salud del trabajador o trabajadora. En consecuencia, la falta de mecanismos judiciales o extrajudiciales, o su ineficacia, atenta directamente sobre la tutela judicial efectiva y la posibilidad de que las víctimas puedan hacer valer sus pretensiones.

Adicionalmente, la Corte consideró que el señor Spoltore, si bien tuvo acceso a un mecanismo judicial de reparación, este no fue brindado de manera expedita y eficaz ni se tuvo en cuenta que se trataba de una persona en condiciones de extrema vulnerabilidad, en este caso, con una discapacidad total declarada del $70 \%$.

Para finalizar, a la luz de la lectura dada por la Corte IDH, el derecho a condiciones equitativas y satisfactorias que aseguren la salud de las personas trabajadoras no resulta una obligación mediata o progresiva que conforme a recursos disponibles los Estados deben adoptar e ir plasmando es sus legislaciones, sino que configura una obligación de exigi-

\footnotetext{
21 Hay que recordar que tanto la Corte Interamericana de Derechos Humanos como la CIDH han sostenido que la Declaración Americana de Deberes y Derechos del Hombre, a pesar de su condición de mera declaración y no de tratado vinculante, igualmente constituye una fuente de obligación internacional para los Estados miembros de la OEA. Ver Opinión Consultiva OC-10/89 del 14 de julio de 1989. Serie A No. 10, párrs. 35-45 "Corte I.D.H. Interpretación de la Declaración Americana de los Derechos y Deberes del Hombre en el Marco del Artículo 64 de la Convención Americana sobre Derechos Humanos".

22 Organización Internacional del Trabajo (OIT). Convenio de la Organización Internacional del Trabajo sobre seguridad y salud de los trabajadores (1981), No 155. Disponible en: https://www.ilo.org/dyn/normlex/es/f?p=NORMLEXPUB:12100:0::NO::P12100_ILO_CODE:C155.
} 
bilidad inmediata, ya que requiere la responsabilidad y el deber por parte de los Estados de adoptar medidas de acción pública que protejan a sus ciudadanos facilitando ciertas garantías judiciales, es decir que puedan hacer valer sus derechos sin discriminación, ante órganos jurisdiccionales imparciales e independientes y obtener una decisión en el menor tiempo posible. Estas obligaciones son exigibles no sólo a los fines de garantizar derechos laborales y de salud reconocidos en el art. 26, sino también en virtud de derechos ya consagrados en la Convención como el acceso a la justicia regulada en el art. 8.1 y en el art 25.1.

En definitiva, ante el incumplimiento por parte de Argentina de las garantías judiciales y la falta de protección judicial, la Corte encontró vulnerado el derecho sustantivo al trabajo en condiciones dignas que garanticen la salud de Victorio Spoltore.

\section{Conclusiones}

A propósito del caso Lagos del Campo vs. Perú, la Corte IDH fija posición en cuanto a que los derechos laborales se encuentran enmarcados dentro del art. 26 de la CADH, que a su vez protege los DESCA contenidos en la Carta de la OEA y por ello son plenamente exigibles. A tales efectos, la persona trabajadora encuentra en el Sistema Interamericano de Derechos Humanos una vía idónea para hacer valer sus derechos frente a un caso concreto una vez agotadas las instancias internas en sus ordenamientos locales.

Manteniendo el mismo criterio, en el fallo Spoltore vs. Argentina, la Corte IDH fue un poco más allá al ampliar el alcance del art. 26 e incorporar el derecho a la salud de las personas trabajadoras como un derecho fundamental. Esto tiene grandes implicancias en los Estados de laregión en el sentido que deberán revisar si los sistemas judiciales e instrumentos legales locales en materia de salud en el trabajo dan respuestas efectivas a los reclamos de protección por parte de los particulares. En efecto, la decisión demuestra una clara dirección en fortalecer el marco protectorio que garantice los derechos de las personas trabajadoras, principalmente en materia de salud, estabilidad y no discriminación.

No obstante, una cuestión donde considero que la Corte debió explayarse con mayor detenimiento es en la situación de especial vulnerabilidad de Victorio Spoltore y la especial protección que merecía atento a las consecuencias que una demora desmedida e injustificada de un proceso judicial laboral podía ocasionarle. A tales efectos, los sistemas judiciales han sido creados para la defensa efectiva de los derechos de las personas, particularmente de aquellas que se encuentran en condición de mayor vulnerabilidad en virtud de los mayores obstáculos que tienen para su acceso o dada la posición desventajosa en que se encuentran en relación al resto dentro del proceso (Alesso y Neder, 2017: 171). En este sentido, en el año 2008, en el marco de la XIV Cumbre Judicial Iberoamericana en Brasilia, se redactaron las 100 Reglas de Brasilia sobre el acceso a la justicia de personas en condiciones de vulnerabilidad en donde el principal objetivo es que los operadores de justicia, englobando el conjunto de políticas, medidas, facilidades y apoyos, permitan a dichas personas el pleno goce de los servicios del sistema judicial .

Si bien la Corte IDH no dispuso otras medidas de reparación o de no repetición que no sean las mencionadas anteriormente, el propio fallo y la interpretación que el Tribunal de San José ha hecho de la Convención ya de por sí configura un valioso antecedente en toda la región en materia de DESCA. En definitiva, la sentencia es en sí misma una herramienta sumamente útil de no repetición, que tanto abogados como abogadas de las 
Américas podrán echar mano en representaciones y alegatos a los fines de hacer valer los derechos de sus clientes.

\section{REFERENCIAS BIBLIOGRÁFICAS}

-Alesso, L. y Neder, M. G. (2017). Proceso Judicial con Perspectiva de Vulnerabilidad. Revista Derecho y Salud, 1, 170-181.

- Calderón Gamboa, J. (2018). La puerta de la justiciabilidad de los derechos económicos, sociales, culturales y ambientales en el Sistema Interamericano: relevancia de la sentencia Lagos del Campo. En Morales Antoniazzi, M., Flores Pantoja, R. y Ferrer MacGregor, E., Inclusión, lus Commune y justiciabilidad de los DESCA en la jurisprudencia interamericana. El caso Lagos del Campo y los nuevos desafíos (pp. 333-379). México: Universidad Autónoma de México.

- Pinto, M. (2009). Integralidad de los derechos humanos. Exigibilidad de los derechos colectivos y acceso a la justicia de las personas en condición de pobreza. Revista IIDH, 50, 53-71.

- Salamero Teixidó, L. (2012). La protección de los Derechos Sociales en el Ámbito de las Naciones Unidas. El nuevo Protocolo Facultativo del Pacto Internacional de Derechos Económicos, Sociales y Culturales. Disponible en línea en: https://www.ohchr.org/en/ issues/escr/pages/canescrbelitigatedatcourts.aspx.

- Salvioli, F. (2016). Indivisibilidad e interdependencia de los derechos humanos como criterios rectores para el trabajo de los órganos convencionales de monitoreo: la relación contemporánea entre los pactos internacionales de los derechos civiles y políticos, y de derechos económicos, sociales y culturales. En Cançado Trinidade, A., Barros Leal, C. y Zerbini Ribeiro Leão, R., Catálogo O Cinquentenário Dos Dois Pactos de Dereitos Humanos da ONU, Vol. 1 (pp. 69-133). Ed. Fortaleza. 